\title{
Organic Ligands Made Porous: Magnetic and Catalytic Properties of Transition Metals Coordinated to the Surfaces of Mesoporous Organosilica
}

\author{
By Andreas Kuschel, Martin Luka, Martin Wessig, Malte Drescher, \\ Mikhail Fonin, Gillian Kiliani, and Sebastian Polarz*
}

Inorganic solids with porosity on the mesoscale possess a high internal surface area and a well-accessible pore system. Therefore, it is a relevant task to equip the suraces of such materials with a maximum density of various organic functional groups. Among these functions it is the capability of coordinating to metal species as a ligand that is of extraordinary importance in many areas, for example, in catalysis. This paper describes how prominent ligands containing donor functions such as carboxylic, thio, chelating; or amine groups can be obtained in the form of nanoporous organosillea

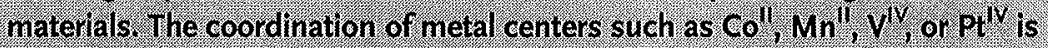
studiedin detail. The magnetic properties of the corresponding materials and some applications in catalysis are reported. A quantitative deterinination of the surface density of donor atoms by distance measurements using EPR spectroscopy is shown.

\section{Introduction}

The coordination of metal cations by ligands is one fundamental interaction in chemistry. Both ionic and covalent interactions play a role. Due to its dative nature, coordinative bonding is reversible in a large number of cases. The reversibility is the most important reason for the application of coordination compounds in a large number of different fields. Just a few examples are the binding of alkanethiols on gold surfaces as the basis for the formation of selfassembled monolayers (SAMS), ${ }^{[1]}$ metalorganic framework materials (MOFs), ${ }^{[2]}$ and coordination compounds in homogeneous catalysis and in bioinorganic context.

It is tempting to bridge from catalytically active, molecular compounds to heterogeneous catalysis, ${ }^{[3]}$ and there has been a tremendous and long-lasting effort in the immobilization of molecular catalysts on solid supports. ${ }^{[4]}$ Silica represents the dominant support material because of the numerous possibilities for shaping and surface modification. ${ }^{[5,(6]}$ For instance, silica with an internal surface area of up to $1000 \mathrm{~m}^{2} \mathrm{~g}$ "'11 came into focus after

[*] Prof. S. Polarz, A. Kuschel, M. Luka, M. Wessig, Dr. M. Drescher, Dr. M. Fonin, G. Kiliani

University of Konstanz

Konstanz D-78457 (Germany)

E-mail: sebastian.polarz@uni-konstanz.de the preparation of mesoporous materials like MCM-41 or SBA-15 had been established. ${ }^{[7.8]}$ Several excellent review articles focusing on the application of metal containing meso-SiO $\mathrm{S}_{2}$ in catalysis have already been published. ${ }^{[6,9,10]}$ Different routes are known for the incorporation of metals into meso- $\mathrm{SiO}_{2}$. One relatively simple approach is to add metal compounds directly to the sol leading to the oxide. As a result metals like $\mathrm{Ni}, \mathrm{Mo}, \mathrm{Ti}, \mathrm{Zr}, \mathrm{Ru}$, and so on, have been embedded inside the silica framework where they can be difficult to access. ${ }^{[1]}$ Alternatively, silanol groups pre. sent at the surfaces can bind to certain lowcoordinated metal species (e.g. $\left.\mathrm{PdCl}_{4}{ }^{2-}\right)^{[12]}$ added after material preparation. The chemical surroundings of the metals in the materials prepared by the latter two methods are rather unspecific and not very functional. This is a disadvantage since it is exactly the specific interplay between the metal and the attached ligands that is responsible for the high selectivity and activity in many molecular catalysts. Consequently, there have been major efforts to provide meso- $\mathrm{SiO}_{2}$ equipped with organic groups bearing ligand functionalities.

Grafting with organic groups can be achieved by $\mathrm{Si}-\mathrm{O}$-. Si bond formation using suitable organosilanes like $\mathrm{R}_{3} \mathrm{SiCl}$ (where $\mathrm{R}$ is an organic group) or alkoxide precursors $\left(\mathrm{R}^{\prime} \mathrm{O}\right)_{3} \mathrm{SiR}{ }^{\left[{ }^{13]}\right.}$ Examples are surface modifications with organic amines or more complex functions like surface-bound catalytically active transition-metal complexes, such as the immobilization of a bimetallic, ferrocenecontaining Pd-catalyst on mesoporous silica. ${ }^{[14]}$ A nice review addressing post-functionalized meso-SiO $\mathrm{S}_{2}$ and its application in catalysis has been published by Ying et al. ${ }^{[10]}$ Organic groups can also be introduced by the co-condensation method. ${ }^{[15]}$ The most severe problem associated with the these methods is the inevitable dilution of the organosilica matrix with pure silica. The composition of the materials has to be described as $\left(\mathrm{SiO}_{2}\right)_{1 \ldots x} \bullet\left(\mathrm{RSiO}_{1.5}\right)_{x}$, where $x$ can be as high as $25 \%$, but cases of only $5 \%$ modification have also been reported frequently. ${ }^{[7,16]}$ It is also very difficult to guarantee a homogeneous distribution of the organic groups along the pore surface. A much higher content of organic modification can be reached when sol-gel precursors with a bridging organic group, $\left(\mathrm{R}^{\prime} \mathrm{O}\right)_{3} \mathrm{Si}-\mathrm{R}-\mathrm{Si}\left(\mathrm{OR}^{\prime}\right)_{3}$, are used for the preparation of the so-called periodically ordered mesoporous 
organosilica (PMO) materials reported by Ozin, Inagaki, and Stein independently from each other. ${ }^{[7]}$ Unlike to the co-condensation case, $\left(\mathrm{R}^{\prime} \mathrm{O}\right)_{3} \mathrm{Si}-\mathrm{R}-\mathrm{Si}\left(\mathrm{OR}^{\prime}\right)_{3}$ is used in an undiluted form leading to mesoporous materials with the composition $\mathrm{RSi}_{2} \mathrm{O}_{3}$, thus, with a degree of organic modification of $100 \%$. PMO materials constructed from walls containing bridging $-\mathrm{CH}_{2}-$, $-\mathrm{CH}_{2} \mathrm{CH}_{2} \cdots,-\mathrm{CH}=\mathrm{CH}-\cdots$, , and so on, have been reported among others, and a summary can be found in recent review articles. ${ }^{[1.8]}$ Large attention was also given to PMO materials prepared from precursors containing a bridging phenyl-ring. ${ }^{[1,20]}$ Such PMOs are very interesting because the $\pi-\pi$ interaction between the phenyl rings can induce partial crystallization of the pore walls. ${ }^{[21]}$ A limited number of papers describe PMO materials containing ligand functionality. ${ }^{[22]}$ For instance, the derivatization of the phenyl ring in the corresponding PMOs with amino or sulfonium groups has been reported..$^{[2,24]}$ The authors introduced the functional group by post-functionalization starting from the unmodified phenylene PMO. Consequently, only a fraction of the phenylene groups was functionalized. Matsuoka et al. reported a very interesting study about the attachment of an organometallic $\mathrm{Cr}(\mathrm{CO})_{3}$ fragment to the phenyl ring of the PMO ${ }^{[24]}$ Some papers about catalytic applications of PMOs have also been published, ${ }^{[22,25]}$ for instance Corma et al. reported a material containing a chiral, bridging vanadyl salen complex and its application in catalysis. ${ }^{[26]}$ However, the authors had to dilute their precursors with $\mathrm{Si}(\mathrm{OEt})_{4}$ and therefore the materials might rather be categorized under the co-condensation category rather than PMOs.

The agenda for the current paper is schematically depicted in Scheme 1. A systematic set of PMO-related mesoporous organosilica materials are provided that are characterized by a maximum surface density of functional groups capable for metal coordination. This set includes an anionic oxygen donor, the mesoporous organosilica $\mathrm{RSi}_{2} \mathrm{O}_{3}$ where $\mathrm{R}$ is bridging benzoic acid (UKON2a), which was previously reported without considering its potential for metal complexation. ${ }^{[27]}$ UKON2f constructed from 1,3-diphenyl-1,3-propanedione is reported here for the first time and represents a chelating, oxygen-donor ligand. UKON2e, the material containing dithiobenzoic acid, is the Lewis-softer counterpart of UKON2a and has also never been described before. Finally, the PMO constructed from aniline (UKON2d) is characteristic for a neutral nitrogen-donor-type ligand. The synthesis and characterization of UKON2d has been reported elsewhere, ${ }^{[28]}$ however, without considering its capabilities for the complexation of metals. The coordination of transition metal cations in these materials and the resulting magnetic and catalytic properties will be investigated.

\section{Results and Discussion}

\section{1. $\mathrm{Co}^{2+}$ Coordination in Mesoporous Materials Constructed from Benzoic Acid}

\subsubsection{Materials with Maximum Ligand Density}

The carboxylic group in UKON2a is expected to be capable of binding to a variety of oxophilic transition metal cations like $\mathrm{Co}^{2-1}$, $\mathrm{Mn}^{2+}$, or $\mathrm{Fe}^{3+}$. The coordination of $\mathrm{Co}^{2+}$ is discussed as a representative case (Scheme 2). The resulting material is denoted Co@UKON2a.Co@UKON2a and UKON2a (as a reference) were analyzed by FTIR spectroscopy shown in Figure 1a. The band at $v_{\mathrm{COOH}}=1700 \mathrm{~cm}^{-11}$ is characteristic of the protonated free carboxylic group $(-\mathrm{COOH})$ in UKON2a. The intensity of $v_{\mathrm{COOH}}$ decreased after the treatment with $\mathrm{Co}^{\mathrm{II}}$. while the two new bands at $v=1586$ and $1420 \mathrm{~cm}^{-1}$ are characteristic for the deprotonated, coordinating - $\mathrm{COO}-\mathrm{M}$ group. The presence of cobalt was confirmed by energy dispersive X-ray spectroscopy (EDX), as shown in the Supporting Information (SI-1). The Si-to-Co ratio is $8: 1$, indicating that $25 \%$ of the carboxylate groups are involved in coordination. The materials were also investigated using UV/Vis spectroscopy measured in diffuse reflectance mode (Fig. 1b). The strong absorption band at $\lambda_{\max }=577 \mathrm{~nm}$ indicates the successful immobilization of $\mathrm{Co}^{\mathrm{Il}}$. The band is shifted in comparison to the aqueous $\mathrm{CoCl}_{2}$ solution $\left(\lambda_{\max }=512 \mathrm{~nm}\right)$, which confirms that a significant change in the coordination environment took place $\left(\mathrm{Cl}^{-} \rightarrow \mathrm{PhCOO}^{-}\right)$. Because it is difficult to obtain quantitative information from diffuse reflectance spectra, the solution used for infiltration was also investigated with UV/Vis spectroscopy in transmission mode prior and after infiltration (Fig. 1b). The intensity of the absorption band of $\mathrm{Co}^{\mathrm{Il}}$ decreases due to the immobilization in UKON2a. The decrease in concentration can be determined using the Lambert-Beers law, which then leads to the amount of immobilized cobalt. Furthermore, because the amount of UKON2a and its composition are known it can be concluded that $28.5 \%$ of the benzoic acid groups are involved as ligands, which is in good agreement with the EDX data. The immobilization of $\mathrm{Co}^{\text {II }}$ has no effect on the pore system, as indicated by the constant pore-size-distribution functions and the maximum at a pore size of $D_{\mathrm{p}}=4.0 \mathrm{~nm}$ as determined from $\mathrm{N}_{2}$. physisorption data (SI-2). Because the surface area of the porous material $\left(S_{\mathrm{BET}}=677 \mathrm{~m}^{2} \mathrm{~g}^{-1} ; \mathrm{BET}=\right.$ Brunauer-Emmett-Teller $)$ and the amount of bound $\mathrm{Co}^{\mathrm{II}}$ are known, it can be concluded that the surface density of -... $\mathrm{COOH}$ groups on the pore walls of UKON2a is on the order of 1.2 groups per $\mathrm{nm}^{2}$, assuming that the majority of the $-\mathrm{COOH}$ groups are involved in coordination.

The paramagnetism of $\mathrm{Co}^{2+}$ prohibits the additional characterization of Co@UKON2a using solid-state NMR spectroscopy. Instead electron paramagnetic resonance (EPR) spectroscopy can be applied. The EPR spectra recorded at different temperatures $T=3.5-298 \mathrm{~K}$ are shown in Figure 2a. The spectrum of Co@UKON2a is characterized by a signal at an effective $g$-factor of $g_{e f f} \approx 4.3$ as expected for a high $\operatorname{spin}(\mathrm{S}=3 / 2) \mathrm{Co}^{\mathrm{Il}}$. A signal with low intensity at $g_{\text {eff }} \approx 2(\approx 3350 \mathrm{G})$ can be seen, which has been observed for all UKON materials regardless if metal species are present or not. The latter signal can be assigned to a persistent organic radical that is not considered here in further detail. The $\mathrm{Co}^{\text {II }}$ signals are very broad, indicating a significant magnetic coupling between individual $\mathrm{Co}^{17}$ centers. The EPR susceptibility $\chi_{\mathrm{EPR}} \times$ Tversus $T$ is plotted in Figure $2 \mathrm{~b} . \chi_{\mathrm{EPR}} \times T$ is not constant for temperatures below $100 \mathrm{~K}$ as would be expected for pure paramagnetism. Instead, $\chi_{E P R} \times T$ goes through a maximum at $T \approx 15 \mathrm{~K}$. Since relaxation effects have been excluded by perform. ing power-dependent measurements and signal loss due to highspin-low-spin transitions is unlikely because for $\mathrm{Co}^{\text {II }}$ low-spin systems $\mathrm{g}_{\mathrm{eff}} \approx 2$ is expected, the decrease of $\chi_{\mathrm{EPR}} \times T$ below $15 \mathrm{~K}$ suggests antiferromagnetic coupling at very low temperatures. The temperature dependence of the spectral line shape as well as of 


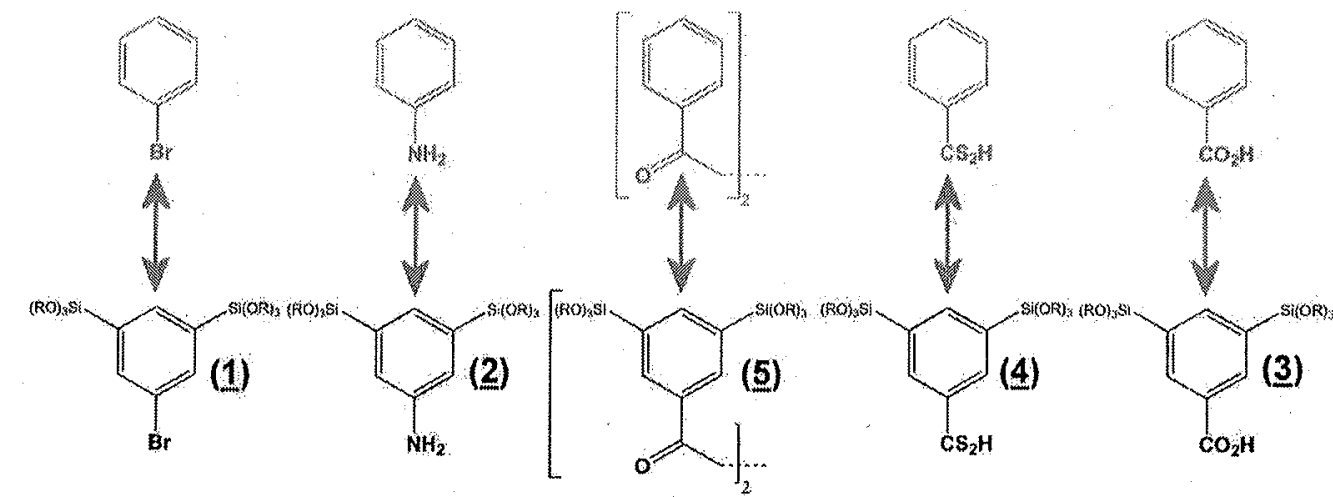

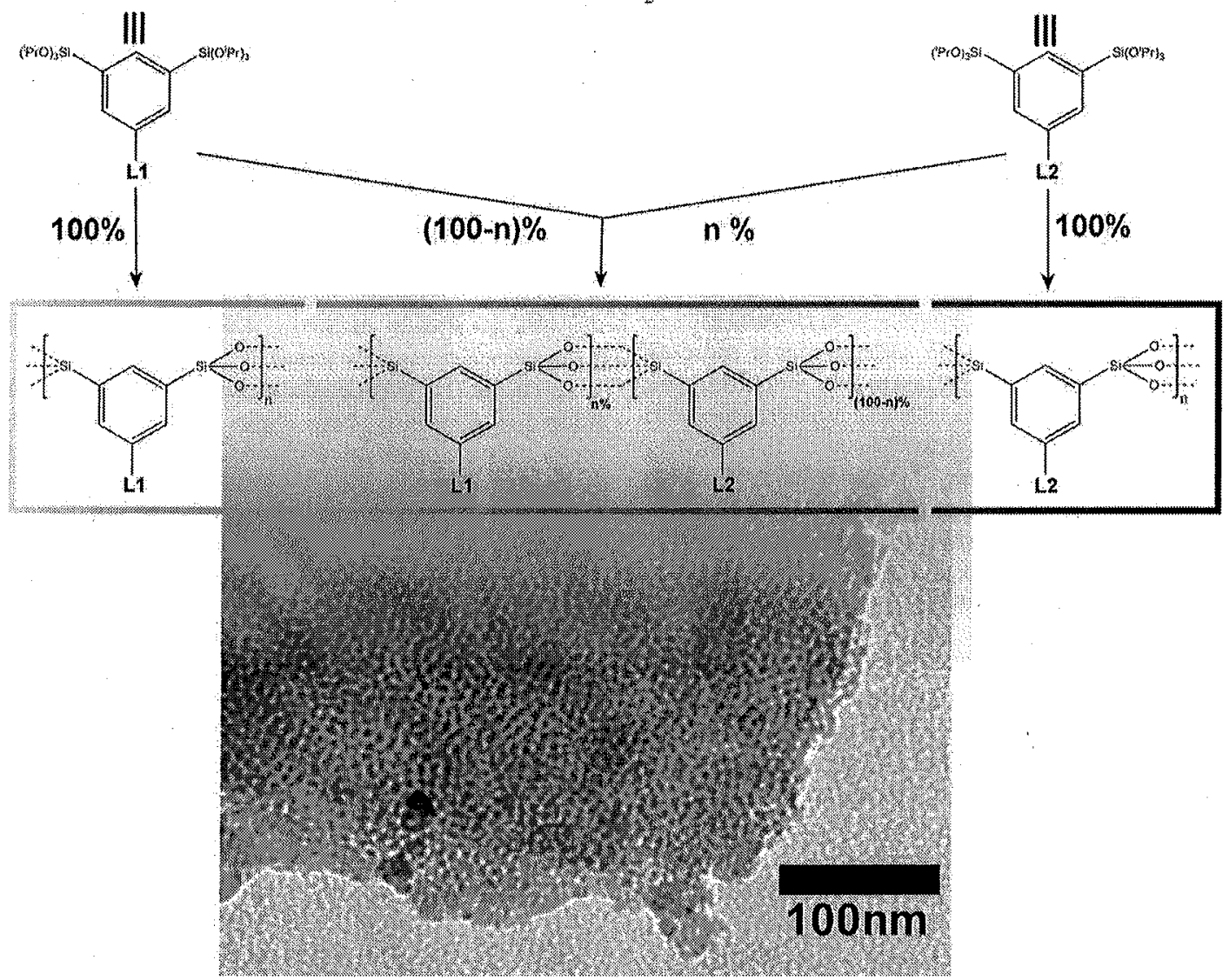

Scheme 1. Roadmap for the preparation of mesoporous organosilica materials composed of important ligands: aniline, benzoic acid, dithiobenzoic acid, and 1,3-dipheny|-1,3-propanedione. 1-Bromobenzene is a reference with no ligand capabilities. The mesoporous materials (UKONs) are prepared using the corresponding sol-gel precursors (1-5). Either the pure precursor or mixtures of two can be used. A TEM micrograph of the mesoporous organosilica material constructed from benzoic acid (UKON2a) is also shown at the bottom.

$g_{\text {erf }}$ is negligible. Nevertheless, the increasing $\chi_{\mathrm{FPR}} \times T$ with decreasing $T$ below $T=100 \mathrm{~K}$ provides evidence that there is a ferromagnetic coupling between the $\mathrm{Co}^{\text {iI }}$ centers. The high density of the ligands in UKON2a and the strong curvature of the 4-nm. wide mesopores could lead to a local clustering of $\mathrm{Co}^{11}$ to superparamagnetic entities at the surfaces. The coupling between the individual $\mathrm{Co}^{11}$ centers is probably achieved via $\mathrm{Cl}^{-}$bridges $(-\mathrm{Co}-\mathrm{Cl}-\mathrm{Co}-)$. The latter assumption fits well to the conclusions drawn from EDX (SI-1) and FTIR (the band at $696 \mathrm{~cm}^{-1} \mathrm{can}$ be assigned $\mathrm{Co}-\mathrm{Cl}$ vibrations; Fig. 1a) that some chlorine is still present due to ferromagnetic coupling between these clusters in the temperature range $80-20 \mathrm{~K}$.

Superconducting quantum interference device (SQUID) measurements were also performed (Fig. $2 \mathrm{c}$ and $\mathrm{d}$ ). Co@UKON2a shows paramagnetic behavior in the $m\left(\mu_{0} H\right)$ where $m, m_{0}$, and $H$ refer to the magnetization, permeability of vacuum, and magnetic field, respectively - curves at $300 \mathrm{~K}$, but a clear ferromagnetic contribution with a remanence of $11-12 \mathrm{mT}$ 


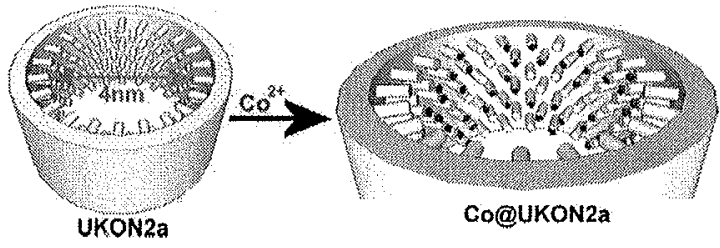

Scheme 2. Cross-section of a pore of the mesoporous organosilica material UKON2a prior to and after coordination of $\mathrm{Co}^{\prime \prime}$. The carboxy groups attached in the 5-position of the phenyl rings are indicated as cylinders covering the surface of the pore. $\mathrm{Co}^{11}$ is shown as small arrows symbolizing the magnetic momentum.

can be seen in the $6 \mathrm{~K}$ measurement (Fig. $2 \mathrm{c}$ ). The $m(T)$ measurements (Fig. 2d) under zero-field-cooled (ZFC) and fieldcooled (FC) conditions show a blocking temperature at about $63 \mathrm{~K}$ and another feature at about $14 \mathrm{~K}$. Furthermore, the splitting in the ZFC/FC curves at $63 \mathrm{~K}$ indicates superparamagnetic behavior of nanoparticles that leads to ferromagnetism below this temperature. The finding of a paramagnetic to ferromagnetic transition leads to the conclusion that by SQUID a different subsystem is probed than by EPR, since EPR does not show any feature at $63 \mathrm{~K}$. The system showing up in SQUID measurements must be spatially separated from the system probed by EPR, since it induces no shift in the EPR lines. Luis et al. developed a model for spherical Co nanoparticles to calculate the particle size if the blocking temperature is known. ${ }^{[29]}$ Applying this model to a blocking temperature of $63 \mathrm{Kresults} \mathrm{in} \mathrm{mean} \mathrm{particle} \mathrm{diameters} \mathrm{in} \mathrm{the} \mathrm{range}$ of $\approx 3 \mathrm{~nm}$. In powder XRD (Fig. 2e) only the diffraction pattern for the amorphous organosilica matrix and no additional crystalline phase is present. However, particles with sizes below $2 \mathrm{~nm}$ can hardly be detected by powder XRD because the reflexes cannot be distinguished from the noise due the significant line broadening. The size of the particles in relation to the pore size $\left(D_{\mathrm{p}}=4 \mathrm{~nm}\right)^{[27]}$ suggests that the effect could originate from pores partially filled with Co. Such nanoparticles could also explain the large remanence field observed in the hysteresis measurement at $6 \mathrm{~K}$. Whether the contribution below $14 \mathrm{~K}$ is also related to these nanoparticles or belongs to another subsystem could not be determined. SQUID cannot detect antiferromagnetism directly so
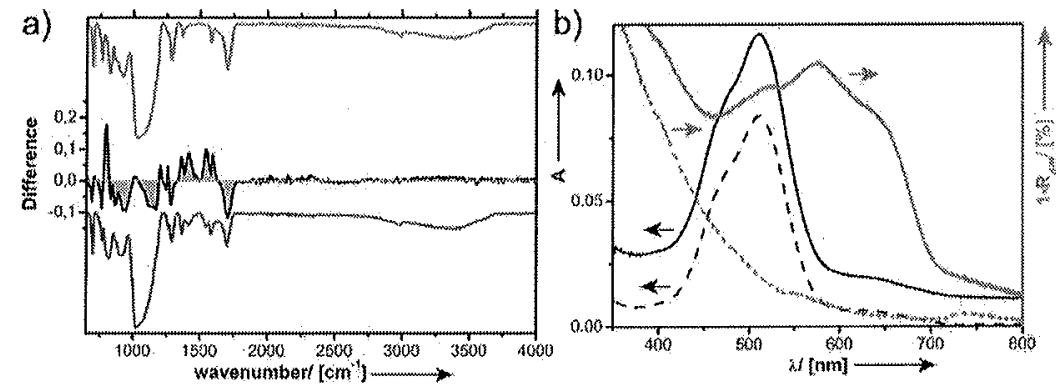

Figure 1, a) FTIR spectra of UKON2a (top curve), Co@UKON2a (bottom curve), and the spectral difference (middle curve). b) UV/Vis spectra of the aqueous $\mathrm{CoCl}_{2}$ solution before and after immobilization of $\mathrm{CO}^{11}$ determined in transmission mode, and of the mesoporous materials UKON2a (grey, dashed curve) and Co@UKON2a (black curve) determined in diffuse reflectance mode. that a change in coupling from ferromagnetic to antiferromagnetic below $20 \mathrm{~K}$ as found in the EPR measurements cannot be confirmed. However, in agreement with EPR a large paramagnetic background contribution was discovered in the $m(H)$ measurements, which is present not only at $300 \mathrm{~K}$ but also at $6 \mathrm{~K}$. Therefore, the case reported here is different to studies in which magnetic effects in mesoporous materials were caused by larger and clearly identifiable nanoparticles (e.g., iron oxide). ${ }^{[30]}$

\subsubsection{Materials with Lower Ligand Density}

In addition to UKON2a, which is characterized by the maximum density of ligand functions, materials with lower density were prepared by diluting the benzoic acid entity (3) with the noncoordinating phenyl-bromide building block (1) (Scheme 1). Then, the composition of the mesoporous materials can be described as $\left(\mathrm{COOHPhSi} \mathrm{O}_{3}\right)_{n}\left(\mathrm{BrPhSi}_{2} \mathrm{O}_{3}\right)_{(100) \cdots n)}$ where $n$ is the relative amount of the benzoic acid ligand in percentage. $n$ was varied from $100 \%$ (UKON2a) to $80 \%, 40 \%, 20 \%, 10 \%, 5 \%$, and $0 \%$ (UKON1). ${ }^{[27]}$ The EPR spectra of the corresponding materials after $\mathrm{Co}^{\text {Il }}$ immobilization are shown in Figure 3a. The magnetic interaction is dependent on composition. The EPR spectrum of the PMO materials containing $80 \%$ of the benzoic acid building block is very similar to the one of UKON2a $(n=100 \%)$. The sample with $n=40 \%$ is already markedly different. The broad signal at $g_{\text {eff }}=4.3$, which is characteristic for the strong magnetic coupling between the $\mathrm{Co}^{\mathrm{Il}}$ centers, decreases strongly with decreasing $n$. Additionally, a very sharp signal appears at $g_{\mathrm{eff}}=4.3$, likely representing more or less isolated $\mathrm{Co}^{\mathrm{n}}$ centers. However, the line width of the broad $\mathrm{geff}=4.3$ signal does not depend on the $\mathrm{Co}^{\mathrm{II}}$ concentration. This observation supports the idea of $\mathrm{Co}^{\text {il }}$ locally clustering on the mesopore surface, which would lead to concentration-independent intracluster distances resulting in identically dipolar broadened EPR spectra.

\section{2. $\mathrm{Co}^{2+}$ Coordination in Mesoporous Materials Constructed from Dithiobenzoic Acid}

The carboxylic group in UKON2a is a rather hard Lewis-base oxygen donor. The corresponding dithiobenzoic acid represents a chemically similar but softer ligand. Because the precursor (3) used for the synthesis of UKON2a (Scheme 1) was prepared by the reaction of 1,3-bis(triisopropoxysilyl)-5-phenyl lithium with carbon dioxide, ${ }^{[27]}$ the analogous reaction was attempted using $\mathrm{CS}_{2}$ instead of $\mathrm{CO}_{2}$ (Scheme 3). The new precursor was characterized by ${ }^{1} \mathrm{H}-,{ }^{13} \mathrm{C}-\mathrm{NMR}$, and FTIR spectroscopies and electron spray ionization mass spectrometry (ESI-MS). The exact mass and isotope pattern for the deprotonated form of precursor (4) ${ }^{\prime}$ was found in ESI-MS (Fig. 4a and b). The corresponding mesoporous organosilica (UKON2e) was prepared under acidic conditions with Pluronic F123 as a structuredirecting agent. UKON2e was characterized by different techniques: small angle X-ray scattering (SAXS), transmission electron 

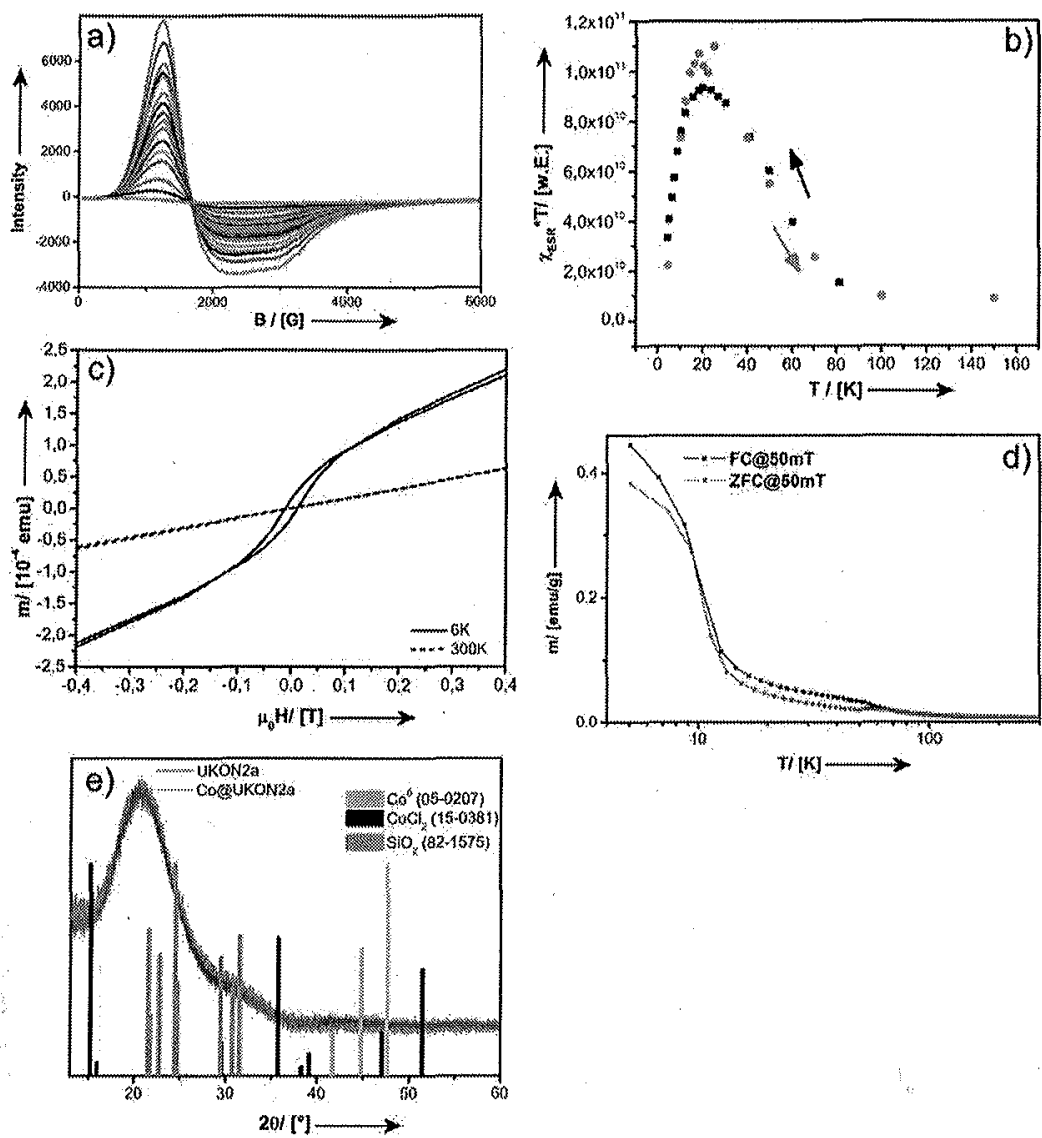

Figure 2. Analytical data for CO@UKON2a. EPR spectra (a), $\chi_{\text {EpR }} \times T$ as a function of $T$ (b), and SQUID measurements $m\left(\mu_{0} H\right)(c), m(T)$ (d), and powder XRD in comparison to UKON2a and diffraction patterns of potential residues (e)
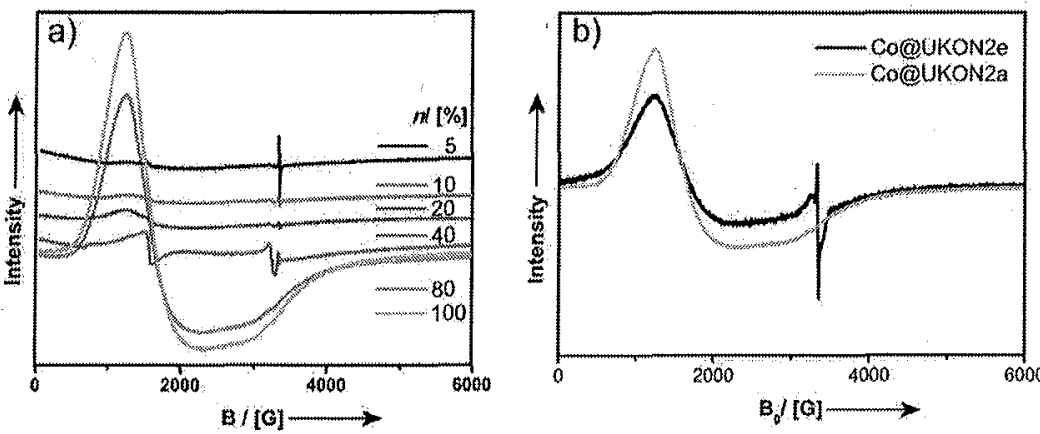

Figure 3. a) EPR spectra of $\mathrm{Co}^{\prime \prime}$ coordinated by mesoporous organosilica materials composed of different amounts of benzoic acid $\left(\mathrm{COOHPhSi} \mathrm{O}_{3}\right)_{n}\left(\mathrm{BrPhSi}_{2} \mathrm{O}_{3}\right)_{(100 \cdots n)}$ and b) by UKON2e in comparison to UKON2a.

microscopy (TEM), $\mathrm{N}_{2}$-physisorption analysis, FTIR spectroscopy, and solid-state NMR spectroscopy (SI-3). The composition of UKONZe is difficult to analyze. Solid-state ${ }^{13} \mathrm{C}$-NMR spectroscopy is hampered by the long relaxation times of the thiocarboxylic group due to the presence of sulfur. ${ }^{[3]}$ As a result only the aromatic carbon atoms are seen as one broad signal at $\delta=142 \mathrm{ppm}$ but the carbon atom attached to sulfur is missing. Unfortunately, the FTIR signals that are significant for the thio groups in (4) $\left(\nu=1115,1018 \mathrm{~cm}^{-1}\right)$ are superimposed by the intense $\mathrm{Si}-\mathrm{O}-\mathrm{Si}$ vibration band at $1070 \mathrm{~cm}^{-1}$ in the organosilica. However, it can be demonstrated by UV/Vis spectroscopy that the absorption maximum determined for the precursor (4) $\left(\lambda_{\max }=508 \mathrm{~nm}\right)$ is also present in UKON2e (Fig, 4c). Only one reflex at a scattering vector $q=0.72 \mathrm{~nm}^{-1}$ (periodicity, $d=8.7 \mathrm{~nm}$ ) can be found in SAXS (Fig. 4d) indicating that a material possessing a worm. hole pore structure has formed, which is also confirmed by TEM. UKON2e possesses a remarkably high BET surface area of $1499 \mathrm{~m}^{2} \mathrm{~g}^{-1}$ and a pore size $D_{\mathrm{p}}$ of $\approx 4.0 \mathrm{~nm}$ according to $\mathrm{N}_{2}$-physisorption data.

For a direct comparison between UKON2a and $2 \mathrm{e}$, the latter was also infiltrated with an aqueous solution of $\mathrm{CoCl}_{2}$. The corresponding EPR spectra are directly compared to each other in Figure 3b. The spectrum of Co@UKON2e also shows the broad signal at $g_{\text {eff }}=4.3$ for the strongly interacting $\mathrm{Co}^{\mathrm{II}}$ species as well as the $g_{\text {eff }} \approx 2$ signal attributed to the pure UKON material.

\section{3. $\mathrm{Mn}^{2+}$ Coordination in Mesoporous Materials Constructed from Benzoic Acid}

$\mathrm{Mn}^{11}$ is expected to be very suited to study the interaction of paramagnetic centers bound to the surfaces of UKON2a in more detail. There is only one stable isotope of manganese with a nuclear spin: $I\left({ }^{55} \mathrm{Mn}\right)=5 / 2$, and the $g$ - and hyperfine tensors are almost isotropic. For high-spin $\mathrm{Mn}^{\text {II }}$ complexes $(\mathrm{S}=5 / 2)$ one typically observes six narrow equidistant lines of equal intensity in EPR spectroscopy. The EPR spectrum of Mn@UKON2a $(n=100 \%)$ clearly indicates the successful immobilization of $\mathrm{Mn}^{\mathrm{II}}$ (Fig. 5a). The characteristic pattern caused by the hyperfine interaction of the ${ }^{55} \mathrm{Mn}$ nuclear spin with the magnetic moment of the unpaired electrons can be identified. The latter signal is superimposed by a broad signal at $g_{\text {eff }}=2.0016$ caused by the dipolar interaction of the magnetic momentum of the individual $\mathrm{Mn}^{1 \mathrm{II}}$ centers. $^{[32]}$ The magnetic susceptibility determined from EPR $\chi$ EPR follows in this case a Curie law $(\chi=C / T, \chi$ and $C$ are the magnetic susceptibility and Curie constant, respectively) as indicated in Figure 5b. For Mn@UKON2a there is no additional coupling except the mentioned dipolar interaction. 


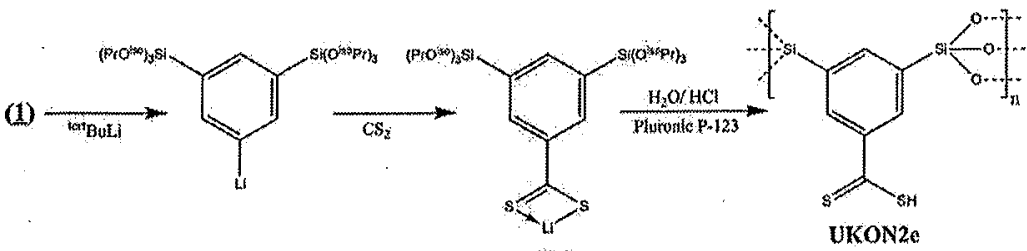

(4)!

Scheme 3. Preparation of the dithiobenzoic acid PMO UKON2e.
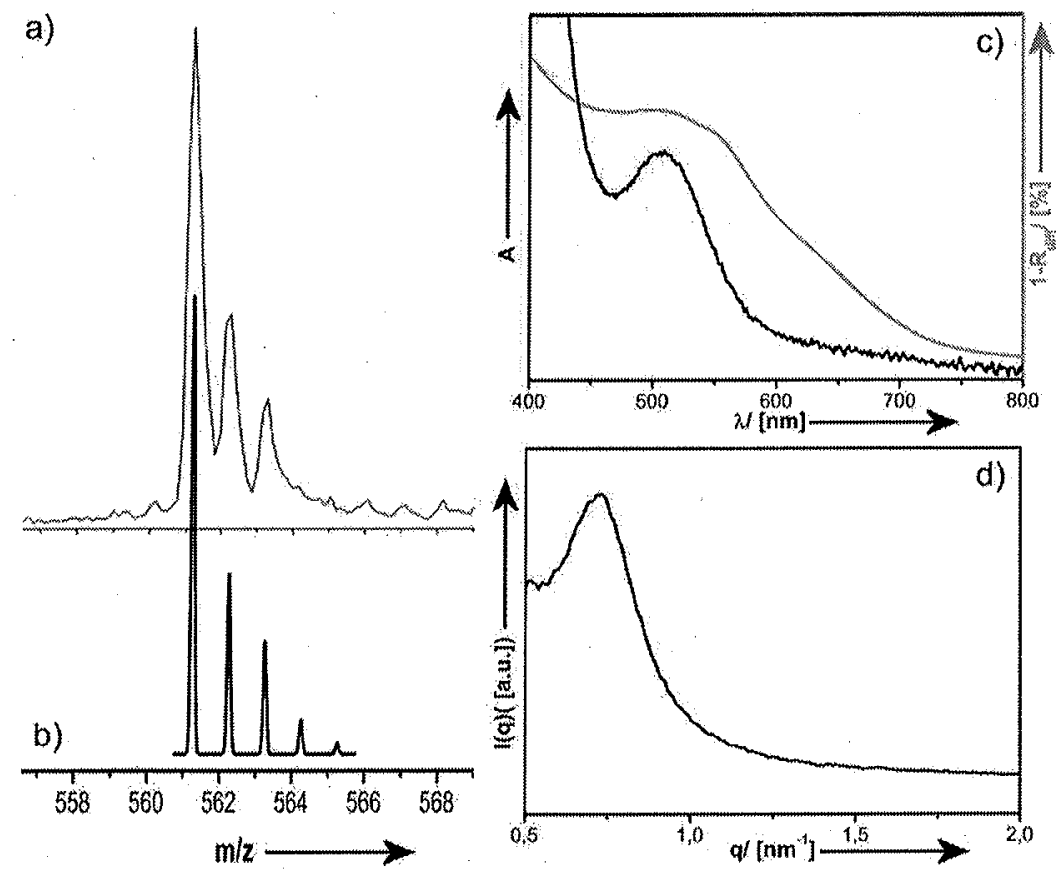

Figure 4. a) Experimental ESI-MS spectrum of precursor (4) in comparison to the simulated pattern for the deprotonated species (b). c) UV/Vis data of the precursor (4) (black graph) in comparison to UKON2e (gray graph), d) SAXS pattern of the mesoporous organosilica materials UKON2e.

The decreasing amount of ligands present in the materials $\left(\mathrm{COOHPhSi}{ }_{2} \mathrm{O}_{3}\right)_{n}\left(\mathrm{BrPhSi}_{2} \mathrm{O}_{3}\right)_{(100 \cdots n)}$ with $n<100 \%$ results in the expected decrease of the $\mathrm{Mn}^{\mathrm{n}}{ }^{\mathrm{s}}$ signal (Fig. $5 \mathrm{a}$ ). In addition, it can be observed that the line width of the individual peaks correlates to $n$ (SI-4). The narrowing can be interpreted as the reduced dipoledipole interaction due to the decreasing density and increasing distance of the carboxylate groups at the surfaces of the mesoporous materials. The peak-to-peak line width $\Delta B_{p p p}$ of the $\mathrm{Mn}^{\mathrm{II}}$ signal is plotted as a function of $n$ in Figure 5c. Because only the dipolar coupling is active it is now possible to estimate from the line width of the EPR signals the average distance between two $\mathrm{Mn}^{\mathrm{II}}$ attached to carboxylic groups (Fig. 5c). The minimal distance $D_{\mathrm{Mn}(\mathrm{II})-\mathrm{Mn}(\mathrm{II})}=1.0 \mathrm{~nm}$ (and maximal density of $\mathrm{PhCOO}$ ) is found for UKON2a $(n=100 \%)$. The latter value leads to a surface density of coordinating carboxylates of 1 group per $\mathrm{nm}^{2}$, which fits very well to the observations described above. $D_{\mathrm{Mn}(\mathrm{II})-\mathrm{Mr}(\mathrm{II})}$ scales linearly with $n$ in the range $100 \%-40 \%$ and at $n=40 \%$ the $\mathrm{Mn}^{\mathrm{II}}$ centers are already 1.6-nm apart from each other. For lower values of $n$ and larger distances the dipole-dipole coupling is not significantly represented in the continuous wave (cw)spectrum anymore, as can be seen in Figure $5 \mathrm{c}$ where $\Delta B_{\mathrm{pp}}$ does not vary for $n<40 \%$. The results shown for the $\mathrm{Mn}^{\mathrm{II}}$. containing samples can only be explained if one assumes that the two building blocks, benzoic acid and bromobenzene, are molecularly dispersed in the pore walls. ${ }^{[28]} \mathrm{A}$ microphase separation does not take place. This result is important because it means that the chemical nature of the pore surfaces can be adjusted.

\subsection{A Mesoporous Organosilica with Walls Constructed from Acac as a Ligand}

Pentane-2,4-dione, respectively acetylacetonate (acac), is a representative of the vital class of chelating oxygen-donor ligands that are used in many important reactions in homogeneous catalysis. ${ }^{[3]}$ Therefore, it is tempting to prepare a mesoporous organosilica material with walls constructed from acac. The necessary precursor (5) has been prepared by a comparably elaborate synthesis shown in Scheme 4. The corresponding, new mesoporous organosilica material UKON2f was obtained from (5) under acidic conditions using Pluronic F123 as a template. The ${ }^{13} \mathrm{C}$-NMR spectrum of UKON2f correlates well to the spectrum of the precursor (5) as a reference (measured in $\mathrm{CDCl}_{3}$ ) (Fig. 6a), indicating that the entire pore walls of UKON $2 f$ are constructed from the acac derivative. The signals at $\delta=20.7$ and $62.0 \mathrm{ppm}$ for the isopropoxy groups have disappeared as anticipated due to their hydrolysis in course of the sol-gel process. Further assignments are shown in Figure 6a. The ${ }^{29} \mathrm{Si}$-NMR spectrum of UKON2f (Fig. 6b) contains the characteristic three signals at $\delta=-70 \mathrm{ppm}$ for $(\mathrm{HO})_{2} \mathrm{RSi}(\mathrm{OSi}) \cong \mathrm{T}^{1}, \quad-77 \mathrm{ppm}$ for $(\mathrm{HO}) \mathrm{RSi}(\mathrm{OSi})_{2} \cong \mathrm{T}^{2}$, and $-86 \mathrm{ppm}$ for RSi(OSi) $)_{3} \cong \mathrm{T}^{3}$. $^{[19]}$ Signals indicating the presence of pure silica $\left(\mathrm{SiO}_{2}\right)$ parts are not seen, demonstrating that the precursor has been used in an undiluted form and that the $\mathrm{Si}-\mathrm{C}$ bonds in UKON2f are stable. The nitrogen isotherm (Fig. 6C) is characteristic of a mesoporous solid..$^{[34]}$ Its internal BET surface area is $1311 \mathrm{~m}^{2} \mathrm{~g}^{-11}$ with an average pore size of $5.1 \mathrm{~nm}$. One reflex at $q=0.67 \mathrm{~nm}^{-1}$ is observed in SAXS (Fig. 6d). This shows that UKON2f possesses a wormhole pore system that has also been checked by TEM measurements (SI-5).

One particularly interesting class of coordination compounds of acac are the vanadyl complexes. The vanadyl cation $\left[\mathrm{V}^{\mathrm{IV}} \mathrm{O}\right]^{2-1}$ is paramagnetic and can also be utilized as a catalyst in various chemical transformations. ${ }^{[35]}$ Therefore, UKON2f was treated with $\mathrm{VO}\left(\mathrm{SO}_{4}\right)_{2}$ (Scheme 5) and the materials were also investigated using EPR spectroscopy. Even after diligent washing the signals 

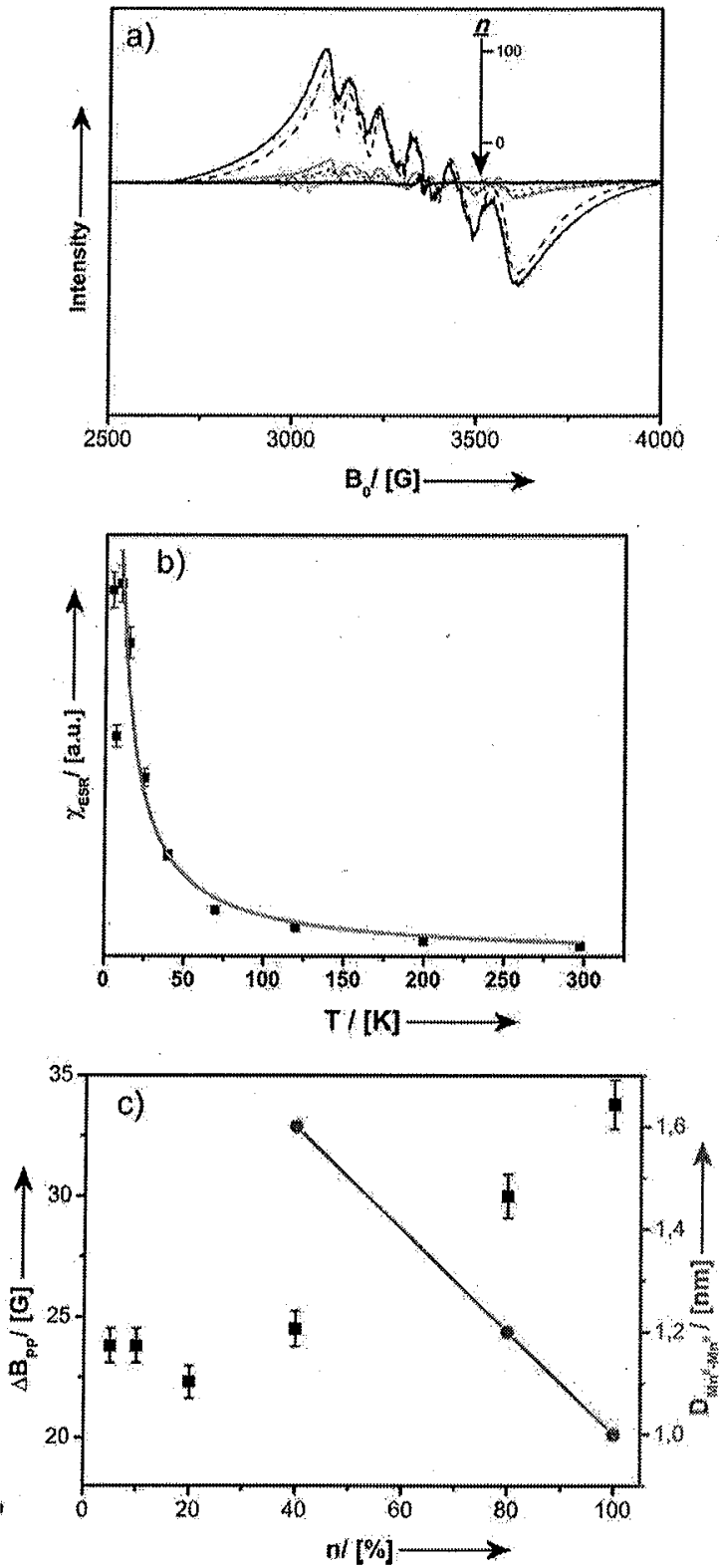

Figure 5. a) EPR spectra of $\mathrm{Mn}^{\prime \prime}$ attached to mesoporous organosilica materials $\left(\mathrm{COOHPhSi} \mathrm{O}_{3}\right)_{n}\left(\mathrm{BrPhSi}_{2} \mathrm{O}_{3}\right)_{(100-n)}$ containing different amount of carboxylic ligand functions. b) Temperature dependency of the magnetic susceptibility determined from EPR data $\chi_{E P R}$ (squares) in comparison to the Curie law (solid line). c) Broadening of the low-field signal (squares) and average distance between two $\mathrm{Mn}^{11}$ centers (circles) as a function of the materials composition $n$.

can be seen that are typical for $\left[\mathrm{VO}^{2+}{ }^{2+}\right.$, implying the superposition of hyperfine-structure lines of ${ }^{51} \mathrm{~V}$ corresponding to the perpendicular and parallel directions of the g-tensor (SI-6). ${ }^{[36]}$ It should be noted that vanadyl complexes are good epoxidation catalysts and others have already used them in mesoporous silica materials. ${ }^{[37]}$ VO@UKON2f was tested in the epoxidation of allyl alcohol with tert-butylperoxide. The progress of the reaction was checked by ${ }^{1} \mathrm{H}$-NMR spectroscopy (SI-7). Furthermore, the catalytic activity of VO@UKON2f was compared directly with the $\mathrm{VO}(\mathrm{acac})_{2}$ and $\mathrm{VOSO}_{4}$ complex in solution. It was found that under identical conditions more of the product glycidol (Scheme 5) is produced with VO@UKON2f as a heterogeneous catalyst than in the homogeneous case (SI-7).

\subsection{A Mesoporous Organosilica with Walls Constructed from Aniline as a Ligand}

Another important class of ligands are monodentate nitrogen donors like amines, for instance aniline. The synthesis and characterization of the corresponding PMO UKON2d has already been described elsewhere, however, without considering its ability to coordinate to metals. ${ }^{[28]}$ When samples of UKON2d are treated with solutions of $\mathrm{Co}^{2+4}$ and $\mathrm{Cu}^{2+4}$ separately, it is seen that both ions can in principle coordinate to the aniline function (SI-8). However, it is expected that UKON2d exhibits a different tendency for coordination to $\mathrm{Cu}^{2+}$ in comparison to $\mathrm{Co}^{2+}$. The latter assumption was tested using a solution containing the two metal species and checking which species is bound more. The UV/Vis spectra of the solution before and after infiltration into UKON2d are shown in Figure $7 \mathrm{a}$. The band at $\lambda_{\text {maxx }}=511 \mathrm{~nm}$ characteristic for $\mathrm{Co}^{2+1}$ has already been mentioned. The band at $\lambda_{\text {rrax }}=808 \mathrm{~nm}$ belongs to $\mathrm{Cu}^{2+}$ in aqueous solution. After infiltration of the solution containing both ions into UKON2d, only the latter band decreased in intensity. UKON2d differentiates effectively between $\mathrm{Co}^{2+}$ and $\mathrm{Cu}^{2+}$ and binds exclusively to copper.

Nitrogen-donor ligands can also coordinate very well to $\mathrm{Pt}^{\mathrm{IV}}$ centers. Therefore, UKON2d was also treated with a solution of $\left[\mathrm{PtCl}_{6}\right]^{2 \cdots}$ (Scheme 6). The resulting material was investigated using solid-state ${ }^{195} \mathrm{Pt}$-NMR spectroscopy (Fig. $7 \mathrm{~b}$ ). $\mathrm{H}_{2} \mathrm{PtCl}_{6}$ was used as a reference, and the chemical shift of the corresponding ${ }^{195} \mathrm{Pt}$ was set to $\delta=0 \mathrm{ppm}$. The coordination to the aniline function in UKON2d leads to a shift of the signal to $\delta=146 \mathrm{ppm}$. ${ }^{[38]}$ Furthermore, because there is only one signal it can be concluded that $\mathrm{Pt}^{\mathrm{IV}}$ coordinates exclusively to the aniline function. It is well known that $\mathrm{Pt}^{\mathrm{IV}}$ complexes represent valuable compounds in homogeneous catalysis. It was tested if Pt@UKON2d is also catalytically active. The hydrosylilation of a substituted alkine (Scheme 6) was selected as a reaction for proof of principle. The reaction was followed by 'H-NMR spectroscopy (SI-9), which showed that Pt@UKON2d successfully catalyzes the hydrosylila. tion reaction.

\section{Conclusion}

Two new mesoporous organosilica materials containing a dithiobenzoic acid building block (UKON2e) and an acac building block (UKON2f) were prepared and characterized. These two materials belong to a larger group of organosilica materials with walls made of organic ligands at $100 \%$. The property of materials containing benzoic acid, dithiobenzoic acid, acac, and aniline regarding the coordination to a variety of metal centers $\left(\mathrm{CO}^{\mathrm{II}}, \mathrm{Mn}^{\mathrm{I1}}\right.$, $\mathrm{Cu}^{\mathrm{II}}, \mathrm{V}^{\mathrm{IV}}, \mathrm{Pt}^{\mathrm{IV}}$ ) was described. The emergence of cooperative 


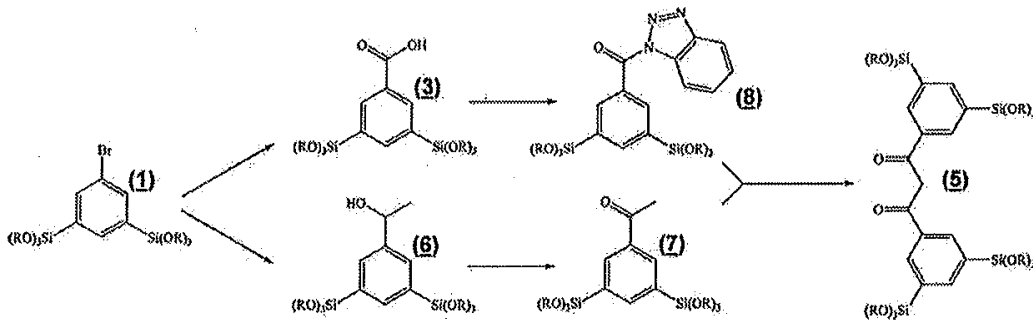

Scheme 4. Synthesis of the 1,5-diphenyl-propane-2,4-dione PMO precursor (5).
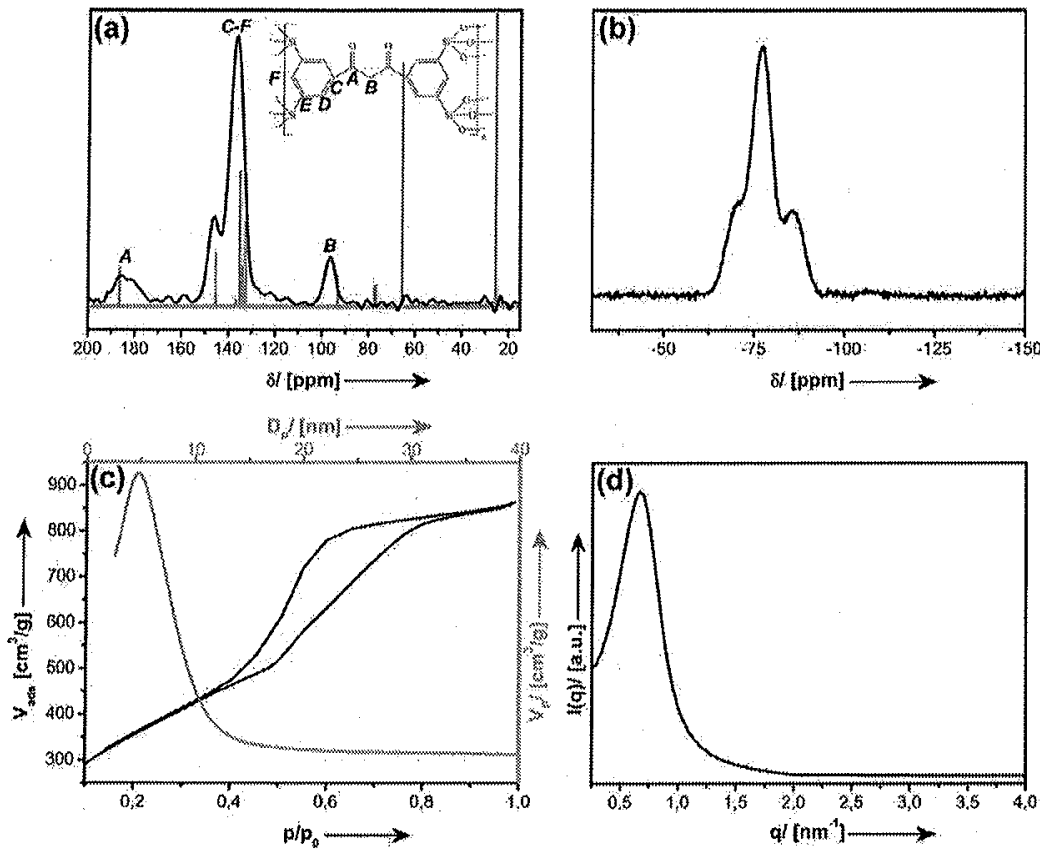

Figure 6. Analytical data for the mesoporous organosilica material UKON2f. a) ${ }^{13} \mathrm{C}$-NMR data of the material (black graph) in comparison to the precursor (5) (gray graph). b) ${ }^{29}$ Si-NMR data. c) $\mathrm{N}_{2}$-physisorption data (black) and BJH pore-size distribution function (gray). d) SAXS data.

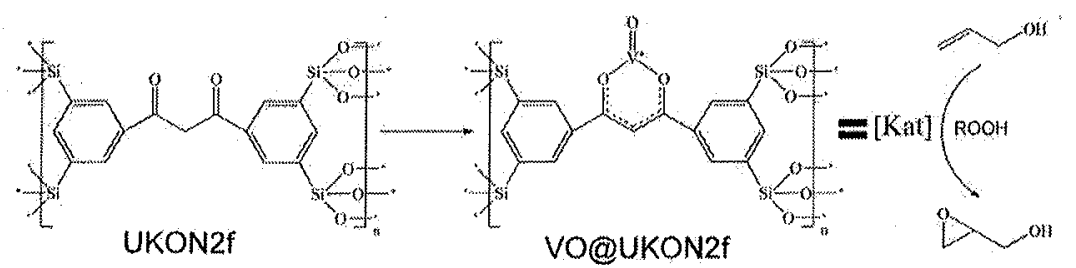

Scheme 5.VO@UKON2f and its use as an epoxidation catalyst.

magnetic phenomena was possible. Various effects were observed ranging from paramagnetism of isolated centers to dipolar coupling and finally to ferromagnetism and antiferromagnetism. The detailed analysis of the magnetic interactions allowed the determination of the distance between two paramagnetic centers bound to the surface. Therefore, it is now possible to give quantitative information about the surface density of ligand functionalities in the mesoporous organosilica materials pre. sented in the current study. The average density of groups capable for metal coordination is $\rho_{\text {surf }} \approx 1.0( \pm 0.1)$ ligand groups per $\mathrm{nm}^{2}$. This value is much higher compared to those that have been reported for mesoporous silica materials post-modified with organic ligands $\left(\rho_{\text {surf }} \approx 0.33 \text { ligand groups per } n^{2}\right)^{[39]}$

\section{Experimental}

General Comments: All starting compounds were received from Sigma-Aldrich. They were carefully purified and dried prior to use, when applicable. All reactions were performed under inert conditions using Schlenck technique. CAUTION: Alkyl-lithium compounds can ignite in contact to air. The compliance of the corresponding security regulations is mandatory. The synthesis of the precursors (1), (2), and (3) has been described previously $[27,28,40]$.

Lithium-3,5-bis(tri-iso-propoxysilyl)-benzodithioic acid (4): 'BuLi $(3.6 \mathrm{~mL}, 6.12 \mathrm{mmol}, 1.7 \mathrm{M}$ solution in hexane) was added to a solution of $1.5 \mathrm{~g} \mathrm{1,3-bis(tri-}$ iso-propoxysilyl)-5-brombenzol (1) $(2.65 \mathrm{mmol})$ in $150 \mathrm{~mL} \mathrm{Et}, \mathrm{O}$ drop by drop at $\ldots . .78^{\circ} \mathrm{C}$. The mixture was stirred $30 \mathrm{~min}$ at this temperature followed by the addition of $15 \mathrm{~mL} \mathrm{CS}(2.49 \mathrm{mmol})$. The color changed from slight orange to dark red. The solution was warmed to room temperature and stirred overnight, during which a white solid appeared. The solvent was removed in vacuum and $60 \mathrm{~mL}$ pentane was added. The non-soluble product was isolated via centrifugation. Pentane was removed and $\mathrm{CH}_{2} \mathrm{Cl}_{2}(60 \mathrm{~mL})$ was added, and the mixture was centrifuged again. The product can be isolated as a dark red solid $(0.8 \mathrm{~g} ; 1.42 \mathrm{mmol} ; 44 \%)$ from the $\mathrm{CH}_{2} \mathrm{Cl}_{2}$ phase. The compound was obtained in the deprotonated form with $\mathrm{Li}^{1 .}$ attached to the ........ function.

'H-NMR (400 MHz, CDCl $3, \delta): 8.93$ (5, 2H, o-Ar H) 8.14 (s, $1 \mathrm{H}, \mathrm{p}-\mathrm{Ar} \mathrm{H}$ ) 4.31 (sept., $J=6.1,6 \mathrm{H}$, $\overline{\mathrm{O}}-\mathrm{CH}), 1.23\left(\mathrm{~d}, J=6.1,36 \mathrm{H}, \mathrm{CH}_{3}\right) ;{ }^{13} \mathrm{C}-\mathrm{NMR}$ $\left(100.61 \mathrm{MHZ}, \mathrm{CDCl}_{3}, \delta\right): 212.2\left(\mathrm{~S}_{2} \mathrm{C}-\mathrm{Ar} \mathrm{C}\right), 148.9$ $\left(\mathrm{S}_{2} \mathrm{C}-\mathrm{ArC}\right), 144.7(\mathrm{Si}-\mathrm{ArC}), 136.3(\mathrm{o}-\operatorname{ArC}), 129.0$ (pAr C), $\overline{66.9}(\mathrm{O}-\mathrm{CH}), \overline{25.6}\left(\mathrm{CH}_{3}\right)$; FTIR (ATR):

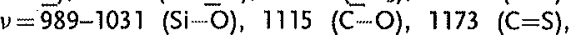
1352-1465 (Ar + aliph. C-..C), 2895-2972 (Ar + aliph. C - H), $3363 \mathrm{~cm}^{-1}(\mathrm{O} \cdots \mathrm{H})$; ESI-MS (m/z): 561.2; UVI VIS (abs): $\lambda_{\max }=509 \mathrm{~nm}$.

UKON 2e: Precursor (4) $(0.29 \mathrm{~g}, 0.52 \mathrm{mmol})$ and $0.16 \mathrm{~g}$ Pluronic $\mathrm{F} 123$ were dissolved in $0.62 \mathrm{~g} \mathrm{EtOH}$. $\mathrm{HCl}(0.15 \mathrm{~g}, 5 \mathrm{M})$ was added drop by drop. The sols were aged in an open container for around one week. The resulting monolithic pieces were dried in vacuum at $100^{\circ} \mathrm{C}$ for $4 \mathrm{~h}$. The template was removed by extraction in $50 \mathrm{~mL}$ EtOH and $50 \mathrm{~mL} \mathrm{HCl}$ (conc.) at $50^{\circ} \mathrm{C}$. Total removal of the Pluronic occurred after $2-4$ days. UKON2e was obtained as an intensively red-colored solid.

Procedure for the Modification of UKON2a, 2d, and $2 e$ with Transition Metal lons: UKON2a as a representative case: $0.2 \mathrm{~g}$ of UKON2a $(0.89 \mathrm{mmol})$ were treated with $20 \mathrm{~mL} \mathrm{NEt}_{3}$ for the deprotonation of the $\mathrm{COOH}$ groups. After stirring overnight the material was filtered off, washed 

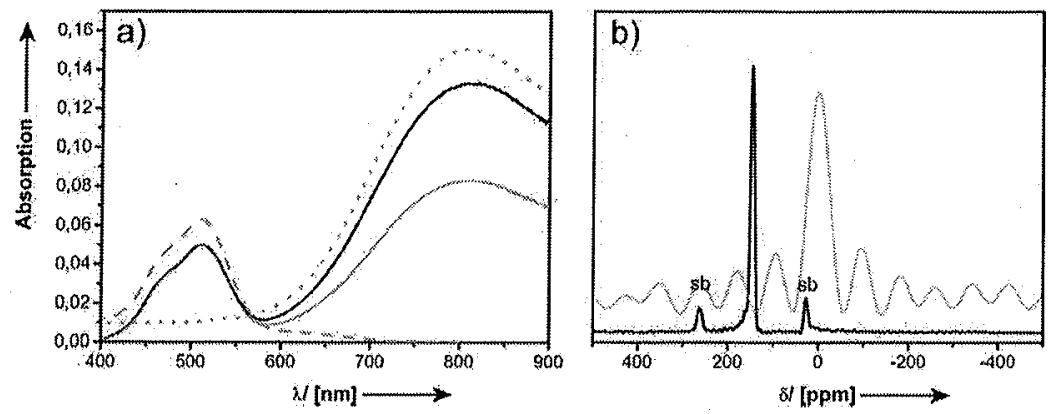

Figure 7. a) UV/VIS spectra of the $\mathrm{Co}^{2++}$ and $\mathrm{Cu}^{2+}$ containing solution before (black solid curve) and after infiltration (gray solid curve) into the mesoporous organosilica material UKON2d. The spectra of a solution of $\mathrm{Co}^{2+}$ (dashed gray curve) and $\mathrm{Cu}^{2+4}$ (dotted gray curve) as references are also shown. b) ${ }^{195} \mathrm{Pt}-\mathrm{NMR}$ spectra of $\mathrm{H}_{2} \mathrm{PtCl}_{6}$ (gray) as a reference and Pt@UKON2d (black)."sb" indicates two spinning side bands.

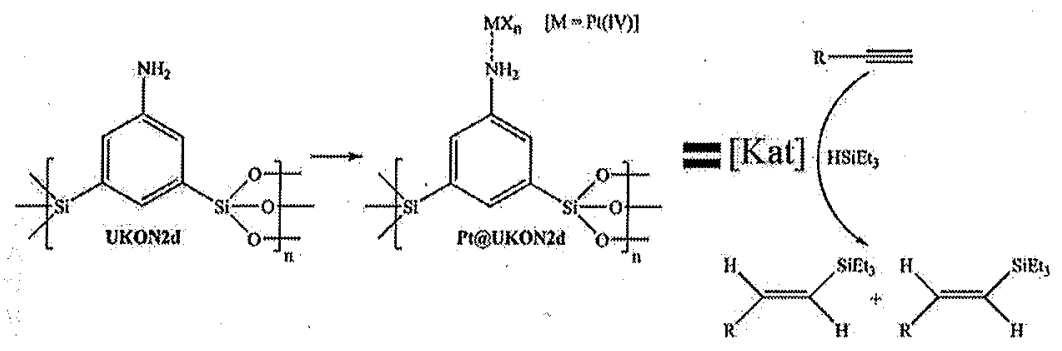

Scheme 6. The preparation of Pt@UKON2d and its use as a catalyst in hydrosylilation. $\mathrm{R}=\mathrm{C}_{6} \mathrm{H}_{5}$.
O- $\left.\mathrm{CH}\left(\mathrm{CH}_{3}\right)_{2}\right), 4.89\left(q, \mathrm{lH}, 3 \mathrm{~J}=6.4 \mathrm{~Hz}, \mathrm{CHCH}_{3}\right)$, $7.72(\mathrm{~m}, 2 \mathrm{H}, 0 . \mathrm{Ar} \mathrm{H}), 7.92(\mathrm{t}, 1 \mathrm{H}, 4 \mathrm{~J}=1.2 \mathrm{~Hz}, \mathrm{p} \cdot \mathrm{Ar}$ H); ${ }^{13} \mathrm{C}$-NMR $\left(62.9 \mathrm{MHz}, \mathrm{CDCl}_{3}, \delta\right): 25.0\left(\mathrm{CHCH}_{3}\right)$, $25.4 \quad\left(\mathrm{CH}\left(\mathrm{CH}_{3}\right)_{2}\right), \quad 65.6 \quad\left(\mathrm{O}-\mathrm{CH}\left(\mathrm{CH}_{3}\right)_{2}\right), \quad 70.5$ $\left(\mathrm{OCH}-\mathrm{CH}_{3}\right), 137.9(\mathrm{C}-\mathrm{Ar} \mathrm{C}), 733.6$ (Si-Ar C), 140.8 (0-Ar C), 143.7 (p-Ar C); IR (ATR): $v=1040$ (Si-..O), 1111 (C - O ), 1369-1467 (aliph. + Ar C - C), 2894-2972 (aliph. + Ar C - H), $3421 \mathrm{~cm}^{\cdots-1}(\mathrm{O}-\mathrm{H})$.

7-(3,5-Bis-tri-iso-propoxysilylphenyl)-ethanone (7): Pyridinium chlorochromate $(0.24 \mathrm{~g}, 1.33 \mathrm{mmol})$ was dissolved in $15 \mathrm{~mL}$ dry $\mathrm{CH}_{2} \mathrm{Cl}_{2}$ followed by $0.4 \mathrm{~g}$ 1-(3,5-bis-tri-iso-propoxysilylphenyl)-ethanol $(0.76 \mathrm{mmol})$. The mixture was stirred at room temperature for $4 \mathrm{~h}$ while the color changed from orange to dark brown. After removal of the solvent in vacuum the product was purified via column chromatography (silica gel $60, \mathrm{CH}_{2} \mathrm{Cl}_{2} \rightarrow$ AcOEt). T-(3,5-Bis-tri-iso-propoxysilylphenyl)-ethanone $(0.322 \mathrm{~g}$, $80 \%, 0.608 \mathrm{mmol}$ ) was obtained as a colorless liquid.

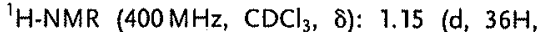
$\left.{ }^{3}=6.1 \mathrm{~Hz}, \mathrm{CH}\left(\mathrm{CH}_{3}\right)_{2}\right), 2.54\left(\mathrm{~s}, 3 \mathrm{H}, \mathrm{CHCH}_{3}\right), 4.21$ (sept, $\left.6 \mathrm{H}, 3=6.1 \mathrm{~Hz}, \mathrm{O}-\mathrm{CH}\left(\mathrm{CH}_{3}\right)_{2}\right), 8.13 \frac{\mathrm{s}}{\mathrm{s}}, 1 \mathrm{H}, \mathrm{p}$ Ar H), $8.24(\mathrm{~s}, 2 \mathrm{H}, 0-\mathrm{Ar} \mathrm{H}) ;{ }^{\top 3} \mathrm{C}$-NMR $(100.61 \mathrm{MHz}$, $\left.\mathrm{CDCl}_{3}, 8\right): 25.6\left(\mathrm{CH}\left(\mathrm{CH}_{3}\right)_{2}\right), 26.7\left(\mathrm{CH}\left(\mathrm{CH}_{3}\right)_{2}\right), 65.7$ $\left(\mathrm{O}-\mathrm{CH}\left(\mathrm{CH}_{3}\right)_{2}\right), 132.0,135.6,136.4,146.1$ (Ar C), $198.5(\mathrm{C}=0) ; \mathrm{IR}$ (ATR): $\nu=1013(\mathrm{Si}-\mathrm{O}), 1116$ $(C-\cdots)$, 1354-1369 (aliph. $+\operatorname{ArC}-\mathrm{C}), 1690(\mathrm{C}=\mathrm{O})$, 2890-2972 $\mathrm{cm}^{-1}$ (aliph. + Ar C-H).

3,5-Bis-tri-iso-propoxysily-benzoly-benzotriazole (8): 3,5-Bis-tri-isopropoxysily-benzoylchloride $(1.0 \mathrm{~g}$ $1.8 \mathrm{mmol}$ ) [40] was added dropwise to a stirred solution of $0.25 \mathrm{~g} 1 \mathrm{H}$-benzotriazole $(2.1 \mathrm{mmol})$ in $20 \mathrm{~mL} \mathrm{CH} \mathrm{Cl}_{2}$ and $5 \mathrm{~mL} \mathrm{NEt}_{3}$ at $0{ }^{\circ} \mathrm{C}$. The mixture was stirred for $24 \mathrm{~h}$ at room temperature. The solvent was removed in vacuum and the product was cleaned via centrifugation in $40 \mathrm{~mL}$ pentane. Further

several times with $\mathrm{EtOH}$ and $\mathrm{Et}_{2} \mathrm{O}$, and dried in vacuum at $100^{\circ} \mathrm{C}$ for several hours. Afterwards a concentrated water solution of the desired metal salt $(1.8 \mathrm{mmol})$ was added. The following salts were used: $\mathrm{CoCl}_{2}$ $\mathrm{MnCl}_{2}, \mathrm{CuCl}_{2}$, VOSO $_{4}$. A slight vacuum was applied for $5 \mathrm{~min}$. After stirring overnight the material was separated by filtration and washed several times with $\mathrm{H}_{2} \mathrm{O}, \mathrm{EtOH}$, and $\mathrm{Et}_{2} \mathrm{O}$. To remove non-coordinated metal species from the pores, the material was stirred two times in $80 \mathrm{~mL}$ of water for 1 day. Finally, the resulting solids were dried in vacuum at room temperature for $12 \mathrm{~h}$. In addition, the solutions containing the nonchemisorbed metal cations were investigated by UV/Vis spectroscopy. The change of metal ion concentration was determined using the LambertBeers law. Because the exact amount of porous material was known as well as its surface area, it was possible to calculate the uptake of $\mathrm{M}^{2+}$ per gram of UKON material and the number of $\mathrm{M}^{2+}$ centers per surface area.

Bifunctional Mesoporous Organosilica Containing Two Different Functional Groups: The materials were prepared under the same conditions described for UKON2e $(0.26 \mathrm{~g}$ Pluronic F123, $1.2 \mathrm{~g} \mathrm{EtOH}$, $0.26 \mathrm{~g} \mathrm{HCl}(1 \mathrm{M}))$. Instead of only one precursor, a mixture of two precursors $((1)+(4)$ or $(3)+(4))$ in different ratios was used.

1-(3,5-Bis-tri-iso-propoxysily/phenyl)-ethanol (6): 'BuLi $(3.5 \mathrm{~mL}, 1.5 \mathrm{M}$, $5.3 \mathrm{mmol}$ ) were added slowly via a syringe to a solution of $7.5 \mathrm{~g} \mathrm{(1)}$ $(2.65 \mathrm{mmol})$ in $50 \mathrm{~mL} \mathrm{dry} \mathrm{Et}_{2} \mathrm{O}$. The mixture was stirred for $30 \mathrm{~min}$ and $0.26 \mathrm{~g}$ acetaldehyde $(5.4 \mathrm{mmol})$ was added. After warming up to room temperature a colorless precipitate appeared. The solvent was removed under vacuum. Non-soluble matter was removed via centrifugation in $60 \mathrm{~mL}$ dry pentane. The product was isolated by column chromatography (silica gel 60 ; hexane/ACOEt: $10 / 1 \rightarrow 2 / 1$ ) as a colorless liquid. Finally $0.84 \mathrm{~g} \mathrm{1-(3,5-bis-tri-iso-propoxysilylphenyl)-ethanol}(60 \%, 1.59 \mathrm{mmol})$ was isolated.

'H-NMR (250 MHz, CDCl,$\delta): 1.14\left(\mathrm{~d}, 36 \mathrm{H}, 3 \mathrm{~J}=6.1 \mathrm{~Hz}, \mathrm{CH}\left(\mathrm{CH}_{3}\right)_{2}\right)$, $1.47\left(\mathrm{~d}, 3 \mathrm{H}, 3 \mathrm{~J}=6.4 \mathrm{~Hz}, \mathrm{CHCH}_{3}\right.$ ) 4.25 (sept, $6 \mathrm{H}, 3 \mathrm{~J}=6.1 \mathrm{~Hz}$, purification was applied via column chromatography (silica gel 60 $\left.\mathrm{CH}_{2} \mathrm{Cl}_{2}\right)$. 3,5-Bis-tri-iso-propoxysily-benzoly-benzotriazole $(0.85 \mathrm{~g}, 75 \%$, $1.35 \mathrm{mmol}$ ) was obtained as a colorless liquid.

${ }^{1} \mathrm{H}-\mathrm{NMR}\left(400 \mathrm{MHz}, \mathrm{CDCl}_{3}, \delta\right): 1.16\left(\mathrm{~d}, 36 \mathrm{H},{ }^{3} \mathrm{~J}=6.1 \mathrm{~Hz}, \mathrm{CH}\left(\mathrm{CH}_{3}\right)_{2}\right)$, $4.24\left(\mathrm{sept}, 6 \mathrm{H},{ }^{3} \mathrm{~J}=6.1 \mathrm{~Hz}, \mathrm{O} \cdots \mathrm{CH}\left(\mathrm{CH}_{3}\right)_{2}\right), 7.54\left(\mathrm{t}, 1 \mathrm{H},{ }^{3}\right)=7.9 \mathrm{~Hz} ; 3-\mathrm{ArH}$ (triazole)), 7.61 (t, $1 \mathrm{H}, 3 J=7.9 \mathrm{~Hz}, 4$-Ar $\mathrm{H}$ (triazole)), 8.08 (d, $1 \mathrm{H}$ $3 J=8.3 \mathrm{~Hz}, 2$-H-triazole), 8.26 (s, IH, p-Ar H (Si-Ar)), 8.33 (d, $\mathrm{lH}$, ${ }^{3} \mathrm{~J}=8.3 \mathrm{~Hz}, \quad 4 \cdot \mathrm{H}$-triazol) $, 8.46(\mathrm{~s}, 2 \mathrm{H}, \quad 0-A r \quad \mathrm{H}(\mathrm{Si}-\mathrm{Ar})):{ }^{13} \mathrm{C}-\mathrm{NMR}$ $\left(100.61 \mathrm{MHz}, \mathrm{CDCl}_{3}, 8\right): 24.5\left(\mathrm{CH}\left(\mathrm{CH}_{3}\right)_{2}\right), 64,7\left(\mathrm{O} \cdots \mathrm{CH}\left(\mathrm{CH}_{3}\right)_{2}\right), 113.8$, 119.1, 125.2, 129.2, 131.9, 138.5, 145.6 (Ar $\subseteq$ ), $166.4(\underline{C}=0)$.

1,3-Bis (3,5-bis-tri-iso-propoxysily)-phenvl)propane-1, 3-dione (5): $\mathrm{MgBr}_{2} \bullet \mathrm{Et}_{2} \mathrm{O}$ $(0.43 \mathrm{~g}, 1.58 \mathrm{mmol})$ was dissolved in $10 \mathrm{~mL}$ dry $\mathrm{CH}_{2} \mathrm{Cl}_{2}$. Then $0.34 \mathrm{~g} \mathrm{~T} \cdot(3,5$. bis-tri-iso-propoxysilylphenyl)-ethanone (7) $(0.65 \mathrm{mmol})$ and $0.85 \mathrm{~g} 3,5$-bistri-iso-propoxysily-benzoly-benzotriazole (8) $(0.65 \mathrm{mmol})$ were added The reaction was started via the addition of $0.33 \mathrm{~mL}{ }^{i} \mathrm{PrNEt}_{2}(1.9 \mathrm{mmol})$. was cleaned via centrifugation, followed by column chromatography (silica gel 60 , pentane $\rightarrow$ AcOEt 15/1). 1,3-Bis(3,5-bis-tri-iso-propoxysily)-phenyl)propane-1,3-dione (5) $(0.37 \mathrm{~g}, 55 \%, 0.36 \mathrm{mmol})$ was obtained as a colorless liquid.

'H.NMR (400 MHz, CDCl ${ }_{3} 8$ ): 1.16 (d, $\left.72 \mathrm{H}, 3=6.1 \mathrm{~Hz}, \mathrm{CH}\left(\mathrm{CH}_{3}\right)_{2}\right)$, $4.22\left(\right.$ sept, $\left.12 \mathrm{H}, 3 \mathrm{~J}=6.1 \mathrm{~Hz}, \mathrm{O}-\mathrm{CH}\left(\mathrm{CH}_{3}\right)_{2}\right), 6.76(\mathrm{~s}, 1 \mathrm{H}$, bridging $\mathrm{CH}$. group), $8.13(\mathrm{t}, 2 \mathrm{H}, J \mathrm{~J}=1.1 \mathrm{~Hz}, \mathrm{p}-\mathrm{Ar} H), 8.23\left(\mathrm{~d}, 4 \mathrm{H},{ }^{4} J=1.1 \mathrm{~Hz}, 0-\mathrm{Ar} H\right.$ ); ${ }^{13} \mathrm{C}$-NMR $\left(100.61 \mathrm{MHz}, \mathrm{CDCl}_{3}, 8\right): 24.5\left(\mathrm{CH}\left(\mathrm{CH}_{3}\right)_{2}\right), 64.6\left(\mathrm{O}-\mathrm{CH}\left(\mathrm{CH}_{3}\right)_{2}\right)$, 92.3 (bridging $\mathrm{CH}_{2}$ ), 131.8, 133.2, 134.0, 144.5 (Ar C), $185.6(\mathrm{C}=0)$ ) IR (ATR): $\nu=1028$ (Si-O), $1115(\mathrm{C}-\mathrm{O}), 1371-1468$ (aliph. + Ar C-C), 1579 $(C=O), 2892-2975 \mathrm{~cm}^{-1}$ (aliph. +Ar C-H). FAB-MS [M+1]: 1041.

UKON2f: 1,3-Bis(3,5-bis-tri-iso-propoxysilyl)-phenyl)propane-1,3-dione (5) $(0.44 \mathrm{~g}, 0.42 \mathrm{mmol})$ and $0.25 \mathrm{~g}$ Pluronic F 23 were dissolved in $1.2 \mathrm{~mL}$ $\mathrm{EtOH} . \mathrm{HCl}(0.24 \mathrm{~g}, 1 \mathrm{M})$ was added drop by drop. The sols were aged in an open container for around one week. The resulting monolithic pieces were After $24 \mathrm{~h}$ the solvent was removed under vacuum and the mixture 
dried in vacuum at $100^{\circ} \mathrm{C}$ for $24 \mathrm{~h}$. The template was removed by extraction with $25 \mathrm{~mL}$ EtOH $25 \mathrm{~mL} \mathrm{HCl}$ (conc) at $60^{\circ} \mathrm{C}$ for 6 days.

Analytical Methods: NMR spectra were acquired on a Varian Unity INOVA 400 spectrometer using dried $\mathrm{CDCl}_{3}$ as a solvent. Solid-state NMR spectra were recorded using a Bruker DRX 400 spectrometer. The following experimental parameters were used for the measurements. ${ }^{13} \mathrm{C}$ : We used a cross-polarization pulse program, a spin rate of $6 \mathrm{kHz}, 5 \mathrm{~s}$ recycle delay, $2 \mathrm{~ms}$ contact time, and a $\pi / 2$ pulse width of $6.2 \mu \mathrm{s} .{ }^{29} \mathrm{Si}$ : We used a cross polarization pulse program, a spin rate of $6 \mathrm{kHz}, 40$ s recycle delay, $12 \mathrm{~ms}$ contact time, and a $\pi / 6$ pulse width of $2.2 \mu \mathrm{s}$. The TEM images were performed on a Zeiss Libra 120 at $120 \mathrm{kv}$ acceleration voltage. The TEM samples were prepared by shortly dipping a carrier covered with a holey carbon foil (Plano company, S147) in the solution, where the grinded UKON materials were dispersed in tetrahydrofuran. FTIR spectra were recorded by using a Perkin Elmer Spectrum 100 spectrometer using an atteruated total reflection (ATR) unit. SAXS measurements were conducted with a Bruker AXS Nanostar. $\mathrm{N}_{2}$-physisorptions measurements were recorded on a Micromeritics Tristar.

EPR: Experimental Details and Data Analysis: EPR experiments were carried out using a Bruker Elexsys E580X-band spectrometer equipped with an Oxford instruments gas flow cryostat. The Bruker ER 4122 SHQE resonator featuring a quality factor of $Q \approx 2500$ was tuned to the $X$-band frequency $v \approx 9.5 \mathrm{CHz}$. Samples were measured in sealed quartz glass sample tubes; the field sweeps of the static magnetic field $B_{0}$ covered the range from 50 up to $9950 \mathrm{G}$ and recorded to up to 8192 data points. The microwave power level was carefully adjusted to avoid saturation effects, typical modulation amplitudes were $3 \mathrm{G}$. Using Matlab scripts for data post-processing EPR susceptibility $\chi_{E R R}$ was derived by numerically integrating the spectra twice. Dipolar coupling was rated by the second moment of the spectra and used to estimate average distances [41]

SQUID Measurernents: Magnetization measurements were performed as a function of magnetic field $\left[m\left(\mu_{0} H\right)\right]$ and as a function of temperature $[m(T)]$ using a MPMS XLS SQUID by Quantum Design. In fieldudependent measurements magnetic fields up to $5 \mathrm{~T}$ were applied for different temperatures. Temperature-dependent measurements were performed under FC and ZFC conditions in a magnetic field of $50 \mathrm{mT}$.

Pt@UKON2d as a Catalyst for. Hydrosilylation: Phenylacetylene $10.1 \mathrm{~g}$ $1 \mathrm{mmol})$ and triethylsilane $(0.12 \mathrm{~g}, 1 \mathrm{mmol})$ were added drop by drop via syringe to $15 \mathrm{mg}$ Pt@UKON2d. The mixture was stirred $15 \mathrm{~min}$ at room temperature and then transferred into an autoclave $(3 \mathrm{~mL})$. Afterwards the temperature was raised to $85^{\circ} \mathrm{C}$ for $2 \mathrm{~h}$. After cooling to room temperature the catalyst was removed by filtration.

H.NMR $\left(400 \mathrm{MHz}_{1} \mathrm{CDCl}_{3}, \delta\right.$ ): (only characteristic signals) 3.17 (s, $0.11 \mathrm{H}$, acetylene $\mathrm{H}$ ), 5.61 (dd, $0.17 \mathrm{H}, 3=3.1 \mathrm{~Hz}, \mathrm{cis}-\mathrm{H}), 5.90$ (dd, $0.17 \mathrm{H}$, $3=3.1 \mathrm{~Hz}$, cis. $\mathrm{H}$ ), 6.45 (dd, $0.83 \mathrm{H}, 3 \mathrm{~J}=3.1 \mathrm{~Hz}$, trans $\cdot \mathrm{H}), 6.93(\mathrm{dd}, 0.83 \mathrm{H}$, $\mathrm{J}=3.1 \mathrm{~Hz}$, trans-H).

$V=O @ U K O N 2 f$ as an Epoxidation Catalyst: To $0.5 \mathrm{ml}{ }^{\mathrm{t}} \mathrm{BuOOH}(5.5 \mathrm{M}$ solution in decane; $2.75 \mathrm{mmol}) 0.58 \mathrm{~g}$ allylalcohol $(9.9 \mathrm{mmol})$ was added

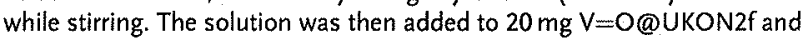
stirred at room temperature for $30 \mathrm{~min}$. Afterwards, the reaction mixture was transferred to an autoclave $(3 \mathrm{~mL})$ and warmed up to $100^{\circ} \mathrm{C}$ for $3 \mathrm{~h}$. After cooling to room temperature the catalyst was removed by filtration.

'H-NMR (400 MHz; CDCl, 8$)$ : (only product signals) $2.24\left(\mathrm{CHH}^{\prime}\right), 2.36$ $\left(\mathrm{CHH}^{\prime}\right), 2.69(\mathrm{CH}), 3.10\left(\mathrm{CHH}^{\prime} \ldots \mathrm{OH}\right), 3.41\left(\mathrm{CHH}^{\prime} \ldots \mathrm{OH}\right)$.

\section{Acknowledgements}

We thank the Zukunftskolleg University of Konstanz for funding. The project is funded by the Deutsche Forschungsgemeinschaft (project SP 780/6-1, DR743/2-1). We thank E. Dormann for stimulating discussions. G.K. ackrowledges financial support from the Carl Zeiss Foundation). Supporting Information is available online from Wiley InterScience or from the author.

Received: November 2, 2009

Revised: December 4, 2009

Published online: March 11, 2010
[1] a) A. Ulman, Chem. Rev. 1996, 96, 1533. b) J. C. Love, L. A. Estroff, 1. K. Kriebel, R. G. Nuzzo, C. M. Whitesides, Chem. Rev. 2005, 105, 1103. c) D. Kafer, G. Witte, P. Cyganik, A. Terfort, C. Woell, J. Am. Chem. Soc. 2006, 128, 1723 .

[2] M. Eddaoudi, D. B. Moler, H. L. Li, B. L. Chen, T. M. Reineke, M. O'Keeffe O. M. Yaghi, Acc. Chem. Res. 2001, 34, 319.

[3] a) D. 1. Cole-Hamilton, Science 2003, 299, 1702. b) G. Jas, A. Kirschning Chem. Eur. J. 2003, 9, 5708.

[4] a) S. Kobayashi, R. Akiyama, Chem. Commun. 2003, 449. b) A. Corma H. Garcia, Adv. Synth. Catal. 2006, 348, 1391. c) F. Cozzi, Adv. Synth. Catal. 2006, 348, 1367.

[5] a) A. Corma, Chem. Rev. 1997, 97, 2373. b) P. Sutra, D. Brunel, Chem. Commun. 1996, 2485. c) B. F. G. Johnson, S. A. Raynor, D. S. Shephard, T. Mashmeyer, J. M. Thomas, G. Sankar, S. Bromley, R. Oldroyd, L. Gladden, M. D. Mantle, Chem. Commun. 1999, 1167.

[6] D. Brunel, Microporous Mesoporous Mater. 1999, 27, 329.

[7] J. S. Beck, J. C. Vartull, W. J. Roth, M. E. Leonowicz, C. T. Kresge K. D. Schmitt, C. T. Chu, D. H. Olson, E. W. Sheppard, S. B. McCullen, J. B. Higgins, ]. L. Schlenker, J. Am. Chem. Soc. 1992, 114, 10834.

[8] a) C. T. Kresge, M. Leonowicz, W. ]. Roth, J. C. Vartuli, I. S. Beck, Nature 1992, 359, 710. b) P. D. Yang, D. Y. Zhao, B. F. Chmelka, C. D. Stucky, Chem. Mater. 1998, 10, 2033, c) D. Zhao, J. Feng, Q. Huo, N. Melosh, G. H. Fredrickson, B. F. Chmelka, G. D. Stucky, Science 1998, 279, 548. d) S. Polarz, B. Smarsly, J. Nanosci. Nanotechnol. 2003, 2, 581.

[9] a) A. Taguchi, F. Schueth, Microporous Mesoporous Mater. 2005, 77, 1 b) M. I. Climent, A. Corma, S. Iborra, M. C. Navarro, 1. Primo, J. Catal. 1996, 161, 783. c) K. Moller, T. Bein, Chem. Mater. 1998, 10 2950.

d) U. Ciesla, F. Schueth, Microporous Mesoporous Mater, 1999, 27, 131.

[10] J. Y. Ying, C. P. Mehnert, M. S. Wong, Angew. Chem. Int. Ed. 1999, 38, 56.

[11] a) A. Corma, M. T. Navarro, 1. Perezpariente, F. Sanchez, Zeolites Relat. Microporous Mater Proc. Int. Zeolite Conf, 10th, 1994, Part A-C 1994, 84, 69. b) T. K. Das, K. Chaudhari, A. J. Chandwadkar, S. Sivasanker, Chem. Commun. 1995, 2495. c) S. Gontier, A. Tuel, Prog. Zeolite Microporous Mater, Proc, Int. Zeolite Conf, 17th, 1996, Part A-C 1997, 105, 1085 d) M. Florea, M. Sevinci, V. I. Parvulescu, G. Lemay, S. Kaliaguine, Microporous Mesoporous Mater. 2001, 44, 483.

[12] L. M. Bronstein, S. Polarz, B. Smarsly, M. Antonietti, Adv. Mater. 2001, 13 1333.

[13] a) E.W. Abel, F. H. Pollard, P. C. Uden, G. Nickless, J. Chromatogr. 1966, 22 23. b) R. K. Gilpin, M. F. Burke, Anal. Chem. 1973, 45, 1383. c) U. Deschler, P. Kleinschmit, P. Panster, Angew. Chem. 1986, 98, 237. d) U. Schubert N. Huesing, A. Lorenz, Chem. Mater. 1995, 7, 2010.

[14] S. A. Raynor, J. M. Thomas, R. Raja, B. F. G. Johnson, R. C. Bell M. D. Mantle, Chem. Commun. 2000, 1925.

[15] a) S. L. Burkett, S. D. Sims, S. Mann, Chem. Commun. 1996, 1367. b) D. J. Macquarrie, Chem. Commun. 1996, 1961.

[16] P. Sutra, D. Brunel, Chem. Commun. 1996, 2485.

[17] a) T. Asefa, M. I. MacLachan, N. Coombs, G. A. Ozin, Nature 1999, 402, 867. b) S. Inagaki, S. Guan, Y. Fukushima, T. Ohsuna, O. Terasaki, J. Am. Chem. Soc, 1999, 121, 9611. c) B. J. Melde, B. T. Holland, C. F. Blanford, A. Stein, Chem. Mater. 1999, 11, 3302.

[18] a) B. Hatton, K. Landskron, W. Whitnall, D. Perovic, G. A. Ozin, Acc. Chem. Res. 2005, 38, 305. b) F. Hoffmann, M. Cornelius, J. Morell, M. Froeba Angew. Chem: int. Ed. 2006, 45, 3216.

[19] C. Yoshina-Ishii, T. Asefa, N. Coombs, M. J. MacLachlan, C. A. Ozin, Chem Commun. 1999, 2539.

[20] a) S. Cuan, S. Inagaki, T. Ohsuna, O. Terasaki, J. Am. Chem. Soc. 2000, 122 5660. b) Y. Goto, S. Inagaki, Chem. Commun. 2002, 2410. c) Q. H. Yang, M. P. Kapoor, S. Inagaki, J. Am. Chem. Soc. 2002, 124, 9694. d) M. P. Kapoor, Q. H. Yang, S. Inagaki, Chem. Mater. 2004, 16, 1209.

[21] S. Inagaki, S. Guan, T. Ohsuna, O. Terasaki, Nature 2002, 476, 304 
[22] S. Fujita, S. Iriagaki, Chem. Mater. 2008, 20, 891.

[23] a) T. Asefa, M. Kruk, M. J. MacLachlan, N. Coombs, H. Grondey, M. Jaroniec, G. A. Ozin, J. Am. Chem. Soc. 2001, 123, 8520. b) M. Ohashi, S. Inagaki, Chem. Commun. 2008, 841 .

[24] T. Kamegawa, T. Sakai, M. Matsuoka, M. Anpo, J. Am. Chem. Soc. 2005, $127,16784$.

[25] Q. Yang, J. Liu, L. Zhang, C. Li, J. Mater, Chem. 2009, 19, 1945.

[26] C. Baleizao, B. Gigante, D. Das, M. Alvaro, H. Garcia, A. Corma, Chem. Commun. 2003, 1860.

[27] A. Kuschel, S. Polarz, Adv. Funct. Mater. 2008, 78, 1272.

[28] A. Kuschel, M. Drescher, T. Kuschel, S. Polarz, Chem. Mater, 2010, DOI: $10.1021 / \mathrm{cm} 903412 \mathrm{e}$.

[29] F. Luis, J. M. Torres, L. M. Garcia, J. Bartolome, J. Stankiewicz, F. Petroff, F. Fettar, I. L. Maurice, A. Vaures, Phys. Rev. B 2002, 65, 094409.

[30] X. Q. Chen, K. F. Lam, Q. J. Zhang, B. C. Pan, M. Arruebo, K. L. Yeung, J. Phys, Chem. C 2009, 113, 9804.

[31] S. Kato, A. Hori, M. Mizuta, T. Katada, H. Ishihara, K. Fujieda, Y. Ikebe, J. Organomet. Chem. 1991, 420, 13.

[32] a) E. Dormann, D. Hone, V. Jaccarino, Phys. Rev. $B$ 1976, 14, 2715. b) E. Dormann, R. D. Hogg, D. Hone, V. Jaccarino, Physica. B + C 1977 86,1183 .

[33] a) O. N. Kharenko, D. I. Epshtein, A. E. loffe, P. M. Darmanyan, Khim Prom-st. (Moscow) 1992, 195, b) J. H. Hanwood, Chem. Process Eng. 1969,
50, 75. c) I. Paal-Lukacs, E. Danoczy, G. Vasvari, D. Gal, Chem. Eng. Commun. 1989, 83, 87. d) A. C. B. Burtoloso, Synlett 2005, 2859. e) S. Zhou, J. Zhang, Huagong Shikan 2007, 21, 22.

[34] a) I. Rouqerol, D. Avnir, C. W. Fairbridge, D. H. Everett, J. H. Haynes, N. Pernicone, J. D. Ramsay, K. S. W. Sing, K. K. Unger, Pure Appl. Chem. 1994, 66, 1739. b) S. J. Gregg, K. S. W. Sing, Adsorption, Surface Area and Porosity, Vol. 2, 4th ed., Academic Press, London 1982.

[35] a) J. C. Vedrine, J. M. M. Millet, J. C. Volta, Catal. Today 1996, 32, 115. b) J. N. Harvey, M. Diefenbach, D. Schroder, H. Schwarz, Int. J. Mass Spectrom. 1999, 182, 85. c) E. I. Baran, J. Inorg. Biochem. 2000, 80, 1.

[36] a) S. Gupta, N. Khanijo, A. Mansingh, J. Non-Cnst. Solids 1995, 181, 58. b) P. J. Carl, S. L. Isley, S. C. Larsen, J. Phys. Chem. A 2001, 105, 4563. c) T. S. Smith, R. LoBrutto, V. L. Pecoraro, Coord. Chem. Rev. 2002, $228,1$. d) E. A. Zamotrinskaya, N. P. Kulemin, Izv. Vyssh. Uchiebn. Zaved, Fiz. 1969, 143.

[37] a) A. Butler, M. J. Clague, G. E. Meister, Chem. Rev. 1994, 94, 625." b) C. Baleizao, B. Gigante, H. Garcia, A. Corma, J. Catal. 2003, 215, 199. c) C. Baleizao, B. Gigante, D. Das, M. Alvaro, H. Garcia, A. Corma J. Catal. 2004, 223, 106.

[38] J. Kramer, K. R. Koch, Inorg. Chem. 2006, 45, 7843.

[39] J. Brown, L. Mercier, T. J. Pinnavaia, Chem. Commun. 1999, 69.

[40] A. Kuschel, S. Polarz, Angew. Chem. Int. Ed. 2008, 49, 9513.

[41] H. J. Steinhoff, Front. Biosci. 2002, 7, C97. 